\title{
Choosing a Power Source of Autonomous Energy-Power Supply of Technological Processes with System Testing for Stability \\ ${ }^{1}$ Vladimir A. Glukharev, ${ }^{2}$ Dmitry A. Solovyev, ${ }^{3}$ Ivan N. Popov, ${ }^{4}$ Andrei A. Verzilin, ${ }^{5}$ Dmitry V. Sivitsky \\ ${ }^{1-5}$ Saratov State Agrarian University named after N.I. Vavilova \\ Email: rector@sgau.ru
}

Received: 20 ${ }^{\text {th }}$ June 2019, Accepted: 05 ${ }^{\text {th }}$ July 2019, Published: $31^{\text {st }}$ August 2019

\begin{abstract}
This paper presents a method for selecting a source of comparable electrical power with a test of stability of an autonomous power supply system, using the example of a process of a grain's preliminary cleaning. The factors of violation of stability due to the feature of starting modes of the node of the electric motor load are considered. An assessment of factors that are taken into account in various approaches to determine source of the power supply is given. The calculated dependencies that consider the power ratio of the powered electric motors and electric generator are proposed, regarding the overload capacity of the generator and function of changing voltage value of the generator when a load is applied.

The voltage drop in system due to the large starting currents of short-circuited asynchronous electric motors is determined for the given parameters of the drive internal combustion engine, and automatic control of the generator excitation.

By checking fulfillment of conditions for stability of the power supply system, the obtained analytical dependencies in relation to determining parameters of an autonomous power supply source for a multi-motor load are solved. The methodical apparatus given here allows the calculation of minimum required power of the power supply source, and determination of the system's performance by checking for stability.
\end{abstract}

\section{Keywords}

Local Power Supply System, Source of Comparable Power, Autonomous Power Supply, Electric Generator, Asynchronous Electric Motor, Voltage Drop, System Stability.

\section{Introduction}

The power supply system is considered as part of the regional energy system as a rule. It includes: power supply centers of the power system, switchgears, substation, power lines of various voltage classes, and consumer receivers.

The centralized generating stations produce electricity, transmit it over long distances, while the grid companies supply electricity to various consumers through medium and low voltage distribution networks. Consumers play a subordinate role in such a system.

Modern infrastructural conditions for the development of rural areas lead to an increase in the energy intensity of consumers. This is particularly related to the quantitative distribution of various electrical units and complexes, and changes in the modes and schedules of electric power consumption, which in turn requires an increase in the length and configuration of electrical networks. But the seasonality of many technological processes in agricultural production causes seasonal demand for heat and electricity, which reduces the feasibility of upgrading and expanding the rural power grid industry.

In this case, it is advisable to switch from the power supply of agricultural enterprises to the power supply of technological processes, and the departure from the centralized power supply to the distributed energy sector, while maintaining the quality of the power supply [1].

For these conditions, one of the actual directions of improving energy supply in the agro-industrial complex is the construction of local energy supply systems, within which the tasks of autonomous power supply for both agricultural enterprises as a whole and technological processes separately can be solved [2,3].

In animal husbandry, first of all, it is necessary to provide the most labor-intensive processes with autonomous power plants, e.g. milking, manure harvesting. In plant growing, the reclamation systems include: pumping and sprinkling machines with electric wheel drive. Grain processing processes: grain loaders, grain cleaning machines and complexes of primary grain processing, grain dryers, grain processing units and complexes. A number of such technologies need both electric and thermal energy, which will make the most efficient use of the potential of electric generators driven by internal combustion engines.

\section{Methodology}

In conducting the present study, theoretical and empirical research methods are used. The main theoretical methods were analysis, synthesis, and modeling. The analysis was carried out through decomposition of all known material, obtained by various researchers on the processes occurring in the link generator - internal combustion engine, into constituent units. From totality of the information obtained through the synthesis, i.e. the association of disparate 
elements of knowledge, a general idea was formed about the phenomenon under study: the stability of the generator during periods of start-up of asynchronous electric motors. On the basis of the received idea of the phenomenon under study, a model of the behavior of the generator link + internal combustion engine was created when an asynchronous electric motor was started. The main empirical methods were observation, comparison, measurement, and analysis of the obtained information. To check the adequacy of the obtained model, observations were made of the work of the generator link + internal combustion engine during the start of asynchronous electric motors in the actual technological process of operation of the mobile grain cleaning complex PZK-30. Measurements were carried out with modern devices: a microprocessor-based electrical process recorder, and current measuring transformers. The obtained information was analyzed at observation, and placed in the created model. Then, the generalization of the obtained results was carried out.

\section{Results}

Considering the possibility of power supply in local systems, special attention should be paid to the stability of operation of such a system [4-6]. Thus, in high-powered electrical systems, instability is most likely in emergency or post-emergency modes. In systems where the power of individual loads is commensurate with power of the system, stability can be disrupted when performing current operations.

The most dangerous thing in this sense, is the direct start of short-circuited asynchronous motors, which usually make up the bulk of the load in the process equipment. Despite the fact that this method of starting is very tough, it is widely used for starting asynchronous electric motors up to $50 \mathrm{~kW}$, in technological schemes for various purposes.

When starting a motor with a short-circuited rotor, it consumes a large starting current. It occurs when the motor is stationary, which is 5-10 times higher than the nominal value. The result is a sharp decrease in voltage, affecting the work of the rest of the operating electric motors and the system as a whole. Reactive power consumed by electric motors increases and causes a further decrease in voltage, which can lead to a stop in the working electric motors, and the impossibility of starting subsequent ones [5].

Therefore, in local power supply systems, in which the power of individual loads is commensurate with the power of the system, stability should be checked according to the conditions of the start of short-circuited electric motors. When starting an asynchronous electric motor from an electric generator of comparable power at the first moment of time, the voltage on the generator tires drops sharply from the initial value $U_{\text {init. }}$ to the minimum $U_{\text {min. }}$ due to the voltage drop in the transient reactance of the generator. In the case of a successful start, it should increase from minimum to the steady state $U_{\text {stead. }}$. For a successful start of the starting motor, the voltage should not decrease to less than 0.6. $U_{\text {nom. }}$ with its subsequent increase to steady-state value $U_{\text {stead-st. }}$ [6].

The electric generator must ensure the start-up of powered motors. Therefore, when choosing a generator set, it is necessary to take into account the ability of the electric generator to withstand short-term current overloads that occur with an increase in power consumption when starting powered motors. For generators with ARV, overload is limited by the magnitude of the short circuit current and is up to $300 \%$ for 10 seconds.

When choosing the power of a power plant with a piston engine, it is also necessary to take into account the requirements arising from the overload capacity of the prime mover, and the peculiarity of the operation of internal combustion engines in the long-term mode. The additional power realized by the primary engine to ensure the regulation function under sudden (accidental) applied ISO load is $10 \%$ of its nominal power [7].

It should also be borne in mind that overestimating the power of the generator set for more gentle perception of starting loads cannot be the right solution, since the recommended load of the generator set with reciprocating internal combustion engines in continuous operation is $80 \%$ of the rated power of the generator set [5].

Given the above limitations, a condition was formulated to determine the power of an electric generator [8]. If there is an electrical load at the start of the electric motor at the terminals of the generator, the inequality for determining the required power of the generator is:

$$
S_{\text {g nom }} \geq \sum_{i=1}^{n-1} \frac{P_{d i} \cdot K_{3 \cdot d i}}{\eta_{d_{i}} \cdot \cos \phi_{d_{i}}}+\frac{1,11 \cdot k_{I} \cdot P_{d_{I}}}{\eta_{d_{I}} \cdot \cos \phi_{d_{I}} \cdot K_{L} \cdot k_{Q}}
$$

Where $S_{\mathrm{g} \text { nom }}-$ generator rated power, $\mathrm{kVA} ; P_{d i}$ - power $i$-th electric motor, $\mathrm{kW} ; K_{\mathrm{zd} i}-$ load factor $i$-th electric motor; $\eta_{d_{i}}$ - efficiency $i$-th electric motor; $\cos \varphi_{d_{i}}$ - Power factor $i$-th electric motor; $P_{d I}$-starting motor power $\mathrm{kW} ; k_{I}$ - frequency of starting current of the electric motor; $\eta_{d I}-$ efficiency of the electric motor being started; $\cos \varphi_{d I}$ - power factor of the electric motor; $k_{Q}$-coefficient taking into account the possibility of generator overload current; $K_{L}$ - coefficient taking into account the overload capacity of the diesel generator in a long mode of operation.

For stable operation in the starting and steady state asynchronous motors, powered by a generator of comparable power, it is necessary that the minimum voltage value of the generator at start-up does not decrease below the allowable, but the function $U^{*}=f(\mathrm{t})$ was monotonically increasing on the interval from zero to the time of the end of the start $\left(0, \mathrm{t}_{\text {start }}\right)$. 
Valid voltages are given in the literature: for engines operating in steady state $U_{\text {stead. }} \geq 0,7 U_{\text {nom. }}$; for engines operating in start mode $U_{\text {stead. }} \geq 0,8 U_{\text {nom. }}$.

Function $U=f(\mathrm{t})$ taking into account the use of APB and the speed controller of the primary motor, is expressed by the exponent [5]:

$U^{*}(t)=\left(1-\Omega_{\max } \mathrm{O}\left[U_{0}^{*}-\left(1-\Omega_{\max }() \frac{K_{0}^{\prime} \Omega \psi_{\max }}{K_{0} T_{d 0}-K_{0}^{\prime} T_{\psi}}\right) e^{\frac{-t}{T_{d 0} \frac{K_{0}}{K_{0}^{\prime}}}}-\frac{K_{0}^{\prime} \Omega \psi_{\max }}{K_{0} T_{d 0}-K_{0}^{\prime} T_{\psi}^{\frac{-t}{T} \psi}}\right]\right)$

Where $\Omega_{\text {max }}$ - maximum deviation of the angular velocity of the generator unit and the engine; $U_{0}^{*}$ - initial voltage value in relative units; $K_{0}^{\prime}-$ circuit resistance factor; $T_{\psi^{-}}$time constant of the prime mover taking into account regulation; $T_{d 0}-$ transient time constant.

Consider the condition of stability of electric motors on the example of the mobile grain cleaning complex PZK30. The self-propelled grain-cleaning complex is intended for preliminary cleaning of weed impurities from the field of grain heap of spikelets, cereals, leguminous crops, and corn, as well as the mechanization of loading work on open currents and in grain stores.

The technological process includes mechanized operations of cleaning and loading grain into motor transport. The operation of the PZK-30 nodes is characterized by the start-up of short-circuited asynchronous motors in the preloaded state.

The main load nodes are asynchronous motors, the parameters of which are presented in table 1 .

\begin{tabular}{|c|c|c|c|c|c|c|c|c|}
\hline Type & $P_{n, k W .}$. & $\mathrm{n}, \mathrm{rpm}$ & $\eta, \%$ & $\cos \varphi$ & $\mathbf{m}_{\max }$ & Mstart $_{\text {st }}$ & $\mathbf{k}_{\mathbf{d}}$ & $\mathbf{I n}_{\mathbf{n}}$ \\
\hline AIR 112MB6 & 4 & 1000 & 82,0 & 0,81 & 2,2 & 2,0 & 6 & 9 \\
\hline 9 AIR 112MA6 & 3 & 1000 & 78,8 & 0,76 & 2,2 & 2,1 & 6 & 7,6 \\
\hline AIR 112MB6 & 4 & 1000 & 82,0 & 0,81 & 2,2 & 2,0 & 6 & 9 \\
\hline 9 AIR 100L4 & 4 & 1500 & 80,2 & 0,81 & 2,3 & 2,3 & 7 & 9,3 \\
\hline
\end{tabular}

Table 1: Technical Specifications of Electric Motors

According to expression (1), for a given technological procedure to start electric motors, taking into account the ability of the generator to withstand short-term current overloads and the overload capacity of the prime mover, the required generator power is determined:

$$
S_{\text {g nom }} \geq 28,4 \mathrm{~kW}
$$

To analyze the startup modes of asynchronous electric motors from a source of comparable power, a synchronous generator has been selected, the parameters of which are given in Table 2.

\begin{tabular}{|c|c|c|c|c|c|c|c|c|c|}
\hline $\mathbf{S}_{\mathbf{g} \text { nom, }} \mathbf{k W}$ & $\mathbf{P}_{\mathbf{g} \text { nom, } \mathbf{k W}}$ & $\mathbf{I}_{\mathbf{n},} \mathbf{A}$. & $\mathbf{c o s} \boldsymbol{\varphi}$ & $\mathbf{h}_{\mathbf{g}}$ & $\mathbf{x}_{\mathbf{d}}$ & $\mathbf{x}_{\mathbf{q}}$ & $\mathbf{x}_{\mathbf{d}}^{\prime}$ & $\mathbf{R}_{\mathbf{s t}}, \mathbf{O} \mathbf{O m}$. & $\mathbf{G D}_{\Gamma}^{\mathbf{2}}, \mathbf{k g m}^{\mathbf{2}}$ \\
\hline 31 & 25 & 45 & 0,8 & 0,87 & 1,97 & 0,99 & 0,11 & 0,02 & 2,4 \\
\hline
\end{tabular}

Table 2: Technical Characteristics of the Synchronous Generator.

The generator rotates the primary engine (diesel), the technical characteristics are given in table 3 .

\begin{tabular}{|c|c|c|c|c|c|c|}
\hline \multirow{2}{*}{ Type } & \multirow{2}{*}{$\mathbf{P}_{\text {dies, }} \mathbf{k W}$} & \multirow{2}{*}{$\mathbf{G D}_{\mathbf{d}}^{\mathbf{2}}, \mathbf{k g m}$} & \multicolumn{4}{|c|}{ Regulation parameters } \\
\cline { 4 - 7 } & & & $\mathbf{T}_{\mathbf{k}}, \mathbf{s}$. & $\boldsymbol{\alpha} \mathbf{0}, \mathbf{r a d}$ & $\mathbf{K}_{\mathbf{0}}$ & $\boldsymbol{\tau}$ \\
\hline GMC430-32 & 32 & 1,14 & 0,0175 & 0,43 & 0,02 & 0,186 \\
\hline
\end{tabular}

Table 3: Engine Specifications

When considering the choice of a source of comparable power for power supply of technological processes, it is necessary to pay attention to the load during the start-up of electric motors. Figure 1 shows the change in load for a given technological order of start-up of electric motors for the period the grain cleaning complex's operation.

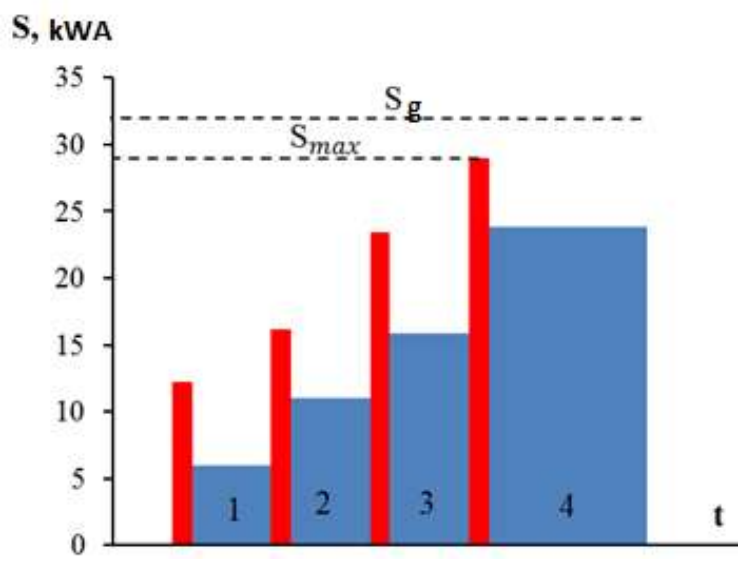

Figure 1: Change in the Estimated Generator Power for the Motor Load Unit for the Period of Operation: (1-4 - Power Values for the Steady-State Mode of the Electric Motors of the Motor Load Unit) 
To determine the voltage change $U^{*}(t)$ with direct start of engines, they can be replaced by a constant load, represented by resistance:

$z_{n}=r_{n}+j x_{n}$

In turn, for the motor to be started:

$$
z_{I}=z_{d}=\frac{\eta_{d_{I}}}{K_{I}} \frac{\cos \varphi_{d_{I}} P_{g}}{\cos \varphi_{g} P_{d_{I}}}\left(\frac{U_{d_{I}}}{U_{g}}\right)^{2}
$$

Load impedance:

$$
z_{\mathrm{H} \sum}=\sqrt{x_{n}+r_{n}}
$$

Respectively:

$$
x_{n}=z_{I} \sin \phi_{p}+x_{c} ; r_{n}=z_{I} \cos \phi_{p}+r_{c},
$$

Where $\cos \phi_{p} ; \sin \phi_{p}$ - at start-up; $r_{c}, x_{c}$ - active and capacitive resistance of the network.

When you start the next, taking into account the presence of working electric motors, expressions (5) will take the following form:

$$
x_{n}=\frac{z_{I} z_{\text {el.work. }} \sin \phi_{p} \sin \phi_{\text {work. }}}{z_{I} \sin \phi_{p}+z_{\text {el.work. }} \sin \phi_{\text {work. }}}+x_{c} ; r_{n}=\frac{z_{I} z_{\text {el.work. }} \cos \phi_{p .} \cos \phi_{\text {work. }}}{z_{I} \cos \phi_{n}+z_{\text {el.work. }} \cos \phi_{\text {work. }}}+r_{c}
$$

Where $z_{\text {el.work.- }}$ equivalent resistance of the working electric motors; $\phi_{\text {work. }}$ - reduced value of the ratio of inductive resistance to active electric motors.

Factor load, pouncing on the unit:

$$
K_{\lambda}=\frac{U_{n o m}^{2} \cos \phi_{a n} P_{g}}{z_{n \Sigma} \cos \phi_{g} P_{p . \mathrm{d}}},
$$

Where $\cos \phi_{\mathrm{a} n}-$ power factor throw load given the active resistance of the stator winding of the generator. The generator voltage at the time of switching on the electric motor will be equal to:

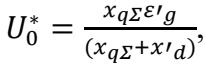

Where $\varepsilon_{g}^{\prime}=1$ of idling; $x_{q \Sigma}$ - load resistance; $x_{d}^{\prime}$ - generator resistance.

Maximum deviation of angular velocity:

At

$$
\Omega_{\max }=\rho K_{\lambda} K_{\delta}\left[e^{-\frac{\alpha}{\beta}\left(\frac{\pi}{2}-\psi+\psi_{0}\right)} \sin \psi_{0}+\cos \psi\right] ;
$$

Respectively:

$$
\rho=\sqrt{\left.\left(1-\alpha \alpha_{0}\right) /\left(\beta \alpha_{0}\right)\right]^{2}+1}
$$

$$
\alpha_{0}=K_{\delta} T_{j} ; \alpha=K_{\delta} T_{j}(1-\tau) /\left(2 T_{m} T_{J}\right) ; \beta=\sqrt{1 /\left(\mathrm{T}_{m} T_{j}-\alpha^{2}\right.},
$$

Where $K_{\delta}$-the degree of irregularity of the regulator (in modern regulators, it is $0.025-0.030$ ); $K_{\lambda}$ - load gain factor; $T_{j}$ - the time constant of the unit (generator and engine); $\tau$ - control pulse lag time; $\mathrm{T}_{m}$ - time constant of the speed controller.

Primary motor time constant with respect to regulation:

$$
T_{\psi}=\frac{\left.0,4\left(\frac{\pi}{2}\right)-\psi+\psi_{0}\right)}{\beta}
$$

At

$$
\psi=\operatorname{arctg}\left[\left(1-\alpha \alpha_{0}\right) /\left(\beta \alpha_{0}\right)\right] ; \psi_{0}=\operatorname{arctg}\left(\frac{\beta}{\alpha}\right) .
$$

Thus, given the parameters of the diesel generator for the first motor to be started, the load throw ratio will be $K_{\lambda 1}=0,49$, and function (2) becomes an exponent of the form:

$$
U^{*}=0,98-0,08 \mathrm{e}^{-2 t}-0,001 e^{-52 t}
$$

The function is monotonically increasing, which is confirmed by the fact that the first derivative does not vanish, hence the stability condition is satisfied.

When starting up the next electric motors, the load-shedding coefficient is respectively: $K_{\lambda 2}=0,53 ; K_{\lambda 3}=$ 0,$75 ; K_{\lambda 1}=1,02$, and with the direct start of the last engine in the technological chain, the starting conditions will be the most difficult.

Voltage change function $U^{*}=f(\mathrm{t})$, for the last engine in the technological chain will look like:

Stability condition is met.

$$
U^{*}=0,97-0,112 \mathrm{e}^{-2,66}-0,002 e^{-52 t}
$$

Figure 3. shows the interpretation of the voltage change in relative units when starting the first and last electric motor from a generator with power $S_{\mathrm{g} \text { nom. }}=31 \mathrm{~kW}$. 


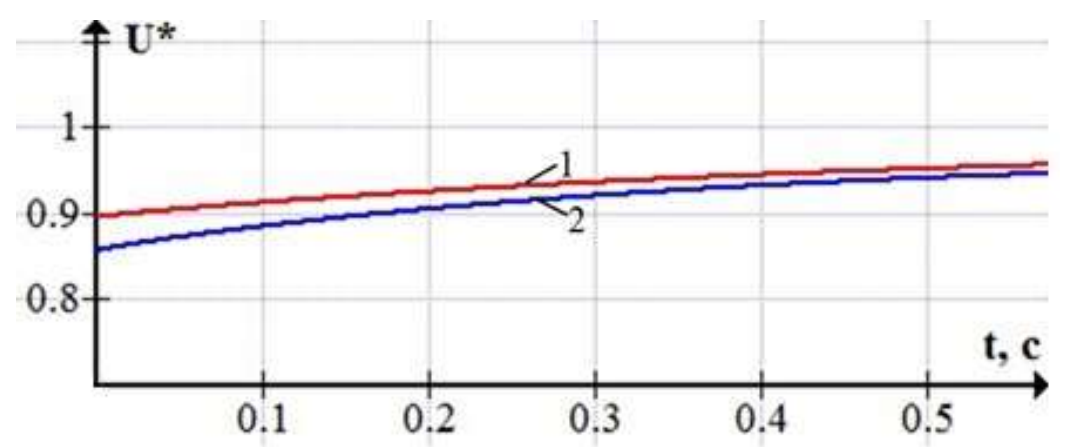

Figure 3: Voltage Change in Relative Units during the Start-up Period for the Generator. $S_{\mathrm{g} \text { nom. }}=31 \mathrm{~kW}$ ( 1 is the First Motor to be Recorded; 2 is the Last Started Electric Motor.)

The decrease in voltage at the initial moment of start-up of the last electric motor is 0.85 , which does not exceed $24 \%$ of the nominal value, according to the ISO 8528-1 standard for the electric generator [9].

From the constructed curves, it can be seen that the direct start of the electric motors powered by the selected generator is successful with the specified starting order.

When considering a similar situation, to power the load node from the generator power $\left(\mathrm{S}_{\mathrm{g} \text { nom. }}=22 \mathrm{~kW}\right)$, which is determined to ensure the operation of electric motors in the steady state mode, the direct start-up of all electric motors is impossible. Checking the stable operation in the starting mode of asynchronous electric motors showed that it was not possible to successfully start the last electric motor. The results are shown in Figure 4.

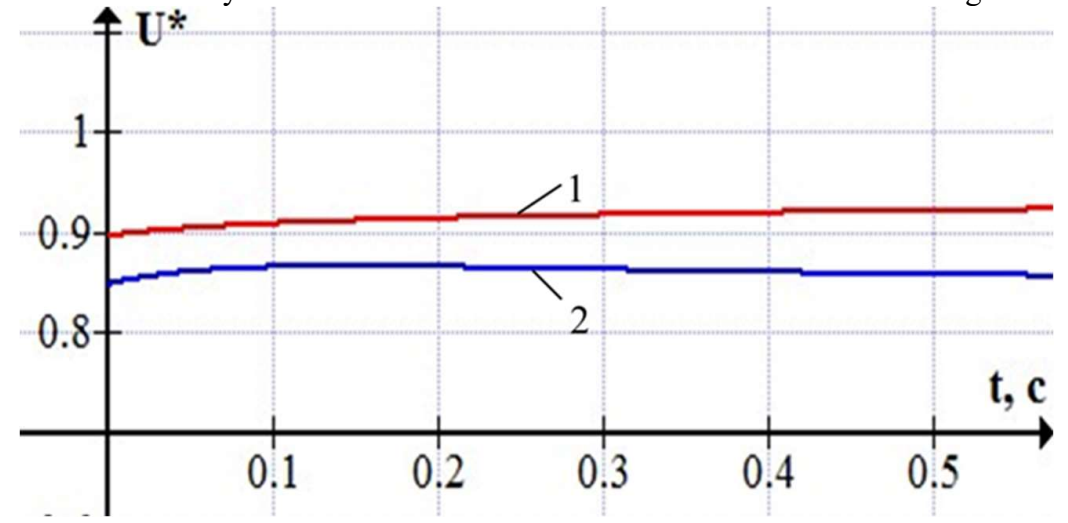

Figure 4: Voltage Change in Relative Units during the Start-up Period for the Generator $S_{\mathrm{g} \text { nom. }}=22 \mathrm{~kW}$ [1-First Electric Motor Started; 2- Last Started Motor (Not Successful Start)]

From the graphs, it can be seen that the start of the first electric motor can be considered successful, since the function of voltage variation $U^{*}$ increases from zero to the end of the start. However, when starting the last motor, the voltage change function $U^{*}$ starts to decrease from 0.1 second. This indicates a further voltage drop in the conditions of a prolonged start, which leads to the inability to perform a successful start.

Thus, as defined by the formulated condition, the required generator power can be used to obtain accurate data when determining the power of an autonomous power source that ensures the stability of the system.

\section{Discussion}

For a broader application of the developed methodology in a production environment, it is necessary to develop a condition for determining the commensurability of generator power and electrical consumers. We have developed recommendations on the choice of the power source power supply, according to the conditions for starting electric motors, i.e. under what conditions it is possible to leave a direct start for all electric motors, and under what measures it is necessary to implement a smooth start for electric motors.

\section{Conclusion}

The proposed method of selecting a generator of comparable power for powering an electromotive load node allows justifying the minimum required rated power of the power supply source, and making a conclusion about performance of system by checking the stability conditions.

It was determined that for the considered motor load node, the minimum required rated power of the power supply source is $41 \%$ higher than the total installed power of the power consumers. 
Checking the stability of the power supply system includes monitoring the voltage recovery at the start of the electric motors, and allows you to determine the performance of the system at the start of each subsequent electric motor.

The calculated voltage drop for the considered motor load unit, with the total power of all installed electric motors is equal to $15 \mathrm{~kW}$, and when choosing a generator $\mathrm{S}_{\mathrm{g} \text { nom. }}=31 \mathrm{kWA}$, makes no more than $15 \%$. The function of voltage variation is monotonously increasing, including in the most difficult conditions, with the direct start of the latter in the technological chain of the electric motor. It indicates the stability and efficiency of the system. When choosing a generator $S_{\mathrm{g} \text { nom. }}=22 \mathrm{kWA}$, while the last electric motor is started, the function of voltage variation is monotonously decreasing. It indicates that the system is not stable, and the voltage drops further in a prolonged start condition, which leads to the inability to perform a successful start.

\section{References}

1. System Atanov I.V., Khorol'skii V.Y., Ershov A.B., Yastrebov S.S. Russian Electrical Engineering. 2018. T. 89. No. 7. P. 428-431.

2. Glukharev V.A., Rykhlov S.Yu., Popov I.N., Verzilin A.A. Using the method of demand coefficient to determine the parameters of the energy systems of agricultural enterprises // Agrarian Scientific Journal - 2016 , - №6. - P.47-51.

3. Autonomous power supply for rural areas, Artyukhov II, Stepanov SF, Molot SV, Tulepova GN, Erbaev ET, Tulegenov KK: 2018 19th. Proceedings 19. 2018. p. 1-4.

4. Choice of the Dynamic of Autonomous Power Supply Systems. Khorol'skii V.Y., Atanov I.V., Mastepanenko M.A., Sharipov I.K. Russian Electrical Engineering. 2018. T. 89. No. 7. P. 425-427.

5. Popov I.N., Rykhlov S.Yu. Justification of the capacity of the generating installation of an autonomous source on the structure of the electrical load of the consumer // Bulletin of Saratov State Technical University. -2014. -№ 3 (76). -WITH. 80-82.

6. Venikov V.A. Transient electromechanical processes in electrical systems: studies. for electrical engineering universities. - 4th ed., Pererab. and add. - M .: Higher. school hours, 1985.- 536s.

7. Electrical generating sets of alternating current driven by an internal combustion engine. Part 5 Electrical: GOST R ISO 8528-5-2011. - M .: Standardinform, 2013. - IV, 26 p.

8. Glukharev, V.A., Popov I.N., Verzilin A.A. Justification of the power generator of the power supply source in the autonomous energy system // Scientific Review. 2017. No. 15. C.68-71.

9. Electrical generating sets of alternating current driven by an internal combustion engine. Application, technical characteristics and parameters: GOST R ISO 8528-1-2005. - Enter 2007 - 01 - 01. Moscow: Standardinform, 2006. I. $16 \mathrm{p}$. 